\title{
Material Frayed
}

National Cancer Institute

\section{Source}

National Cancer Institute. Material Frayed. NCI Thesaurus. Code C63131.

Problem associated with the comprising materials having damaged edges. 